\title{
Modeling of the kinetics of linear and crosslinking photopolymerization. Part III ${ }^{* * *}$
}

\begin{abstract}
Summary - A review with 135 references continuing the comparison of modeling of linear and crosslinking photopolymerizations and covering the gel formation during crosslinking, the gel effect (autoacceleration of polymerization), modeling of the overall rate of polymerization, the rate of polymerization in the photoinduced electron/proton transfer mechanism, the kinetic treatment of photopolymerization by photo-differential (isothermal) scanning calorimetry, and reactivities of radicals and monomers.
\end{abstract}

Key words: photopolymerization, photoinitiators, kinetics of initiation, propagation and termination steps.

\section{GEL FORMATION DURING CROSSLINKING}

Photopolymerization of monomers with the functionality higher than 2 produces a branched polymer (Fig. 1a). The growing branches interact with each other to produce infinite molecular weight crosslinking
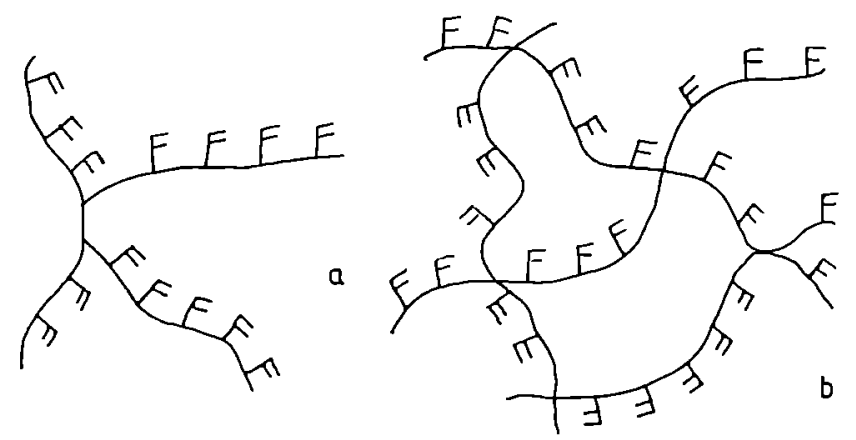

Fig. 1. Schematic presentation of: (a) branched macromolecule (pregel state) and (b) crosslinked net

products (Fig. 2 b) known as gels. Since multifunctional monomers have more than one functional group, each group may possess a different reactivity. In general, this functional group reactivity is not only unequal but it also varies with the degree of conversion of the double bonds in the system. Any polymerization involving multifunctional monomers has this added complexity of possibly varying reactivity of functional groups on

*) Jagiellonian University, Department of Chemistry, Ingardena 3, 30-060 Cracow, Poland. To whom all correspondence should by addressed.

**) Polymer Research Group, Department of Dental Biomaterial Science, Karolinska Institute (Royal Academy of Medicine), Box 4064, 14104 Huddinge (Stockholm), Sweden.

***) For Part II see [1]. the same molecule, what causes structural heterogeneity $[2,3]$. The primary result is the formation of microgel regions early in the reaction, because of high pendant double-bond reactivity [4-8]. Microgels are regions in the system of higher average crosslinking density than that of the overall system, manifested from the strong spatial correlation between pendant group reactivity and radical location [9]. Usually, the crosslinking

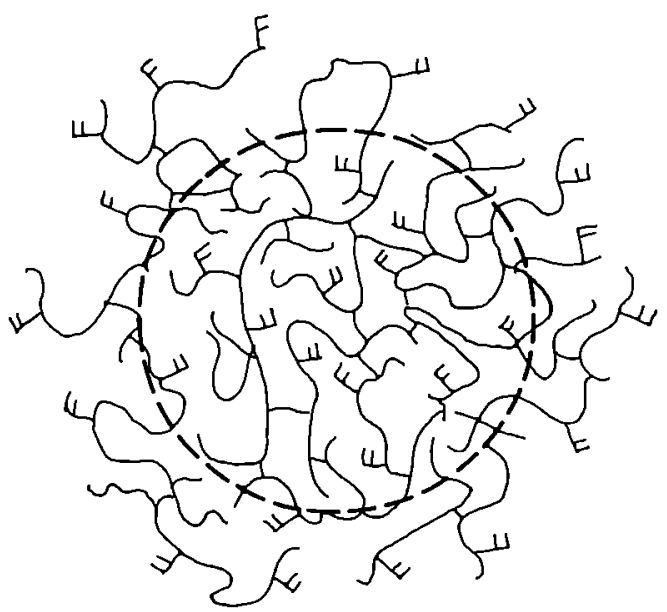

Fig. 2. Schematic presentation of a microgel [10]

photopolymerization forms densely crosslinked microgel regions within a less densely crosslinked area (Fig. 2 ). The microgel regions are formed near the radical initiation sites. It has also been observed that, in the same polymer network, unreacted monomer pools can exist $[7,8]$. This heterogeneity not only affects the reactivity of monomeric and pendant functional groups, but it also affects the material properties [11]. A heterogeneous material may have properties which are dramati- 
cally different from the properties of the corresponding homogeneous material [11-15]. The resulting polymer structures are often extremely difficult to characterize either experimentally and/or theoretically.

When a radical on a polymer chain propagates through a pendant double (i.e. a double bond from a monomer with one double bond that has already reacted), primary cycles, crosslinks and secondary cycles can be formed (Fig. 3) [3, 16, 17]:
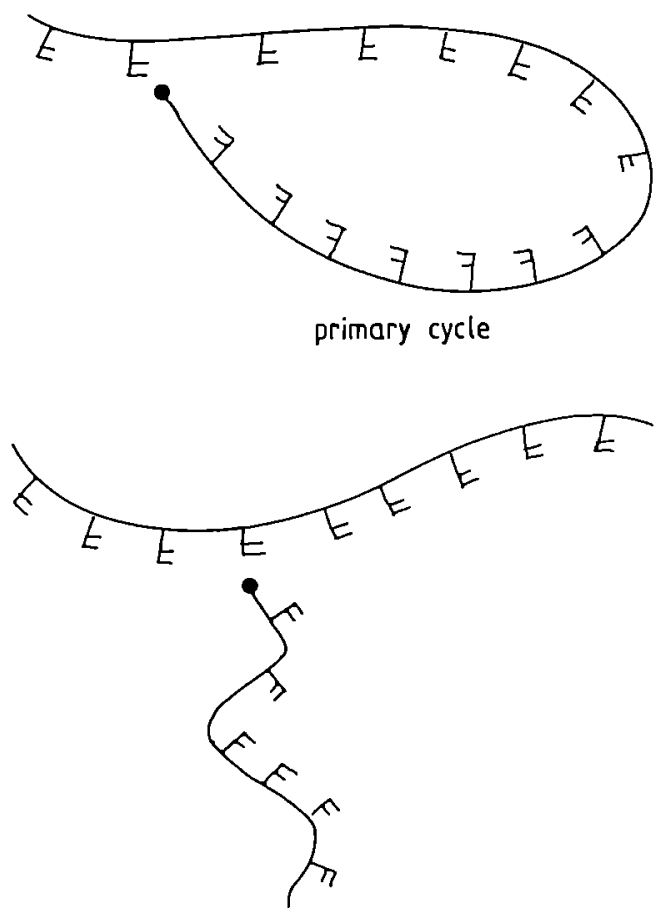

crosslink

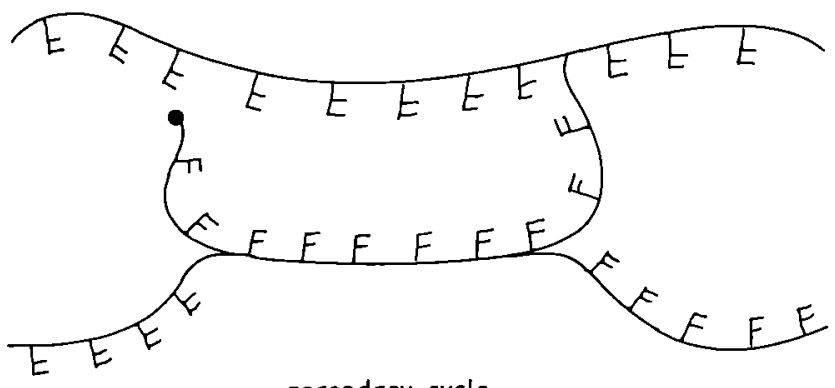

secondary cycle

Fig. 3. Classification of the reactions of pendant double bonds during free radical crosslinking polymerizations [16]

- primary intramolecular cycles result, when propagating radicals react with pendant double bonds on their own kinetic chains;

- intramolecular crosslinks form when the radicals react with pendant double bonds on different kinetic chains;

- secondary intramolecular cycles result when propagating radicals react with pendant double bonds on different kinetic chains with which they are already crosslinked. As the chain flexibility increases, the reactivities of the pendant functional groups are enhanced what leads to extensive cyclization at a low conversion [18-21].

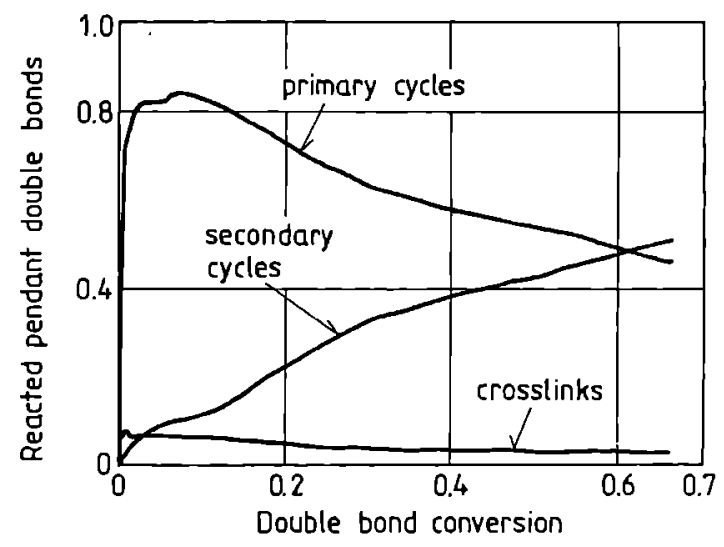

Fig. 4. Kinetic gelation model prediction of the relative fraction of crosslinks, and primary and secondary cycles as a function of double bond conversion in the polymerization of a multifunctional monomer [3]

In Fig. 4. are shown the relative fractions of crosslinks, the primary and secondary cycles as a function of double bond conversion for homopolymerization of a tetrafunctional monomer [3]. Initially, primary cyclization dominates crosslinking and secondary cyclization, as the pendant double bonds have an increased reactivity in the localized region of the free radicals. This behavior accounts for the formation of microgel regions and the heterogeneity of the network. As the conversion and the polymer concentration increase, crosslinking and secondary cyclization begin to increase and a network forms. Finally, a transition region is reached where secondary cyclization and primary cyclization cross over. The trend is now towards a more homogeneous network structure with a very high degree of secondary cyclization [3].

For cyclization to occur, the propagating radical and pendant double bond, attached to the same molecule, need to come into a small reactive volume of the order of Angstroms in size [16]. At low conversions ( $<1-2 \%)$, polymerization is still not diffusion controlled, and the equilibrium concentration of the propagating radical about pendant group is controlling. The time scale for propagation of an individual propagating radicals is generally on the order of $10^{-4}$ to $10^{-3}$ seconds, whereas the time scale for end-to-end cyclization is often of the order of $10^{-7}$ seconds for short chains to $10^{-5}$ seconds for moderately long chains (e.g. $\left.D P_{n}=1000\right)$ [22]. Measuring of the extent of cyclization poses a problem. Chemically, a crosslink and a cycle are equivalent.

The rate of pendant double bonds consumption can be modeled on the assumption that the total pendant consumption rate is the sum of the crosslinking rate and 
the cyclization rate [23]. The rate of consumption of pendant double bonds by crosslinking is analogous to the rate expression for the consumption of monomeric double bonds ( $c f$. [1]). Crosslinking is the function of the kinetic parameter for crosslinking, the concentration of pendant double bonds, and the concentration of radicals in a polymerizing system. The rate of cyclization depends on the kinetic parameter for cyclization, the pendant double bond concentration, and the local radical concentration. The expression is summed over all times in which the pendant groups were created, since the local concentration depends on when the pendant group was created and how far the radical on the same chain has propagated away. The local propagation radical concentration (at time $t$ that have reacted between the radical $\left(R^{\circ}\right)$ and monomeric double bond that

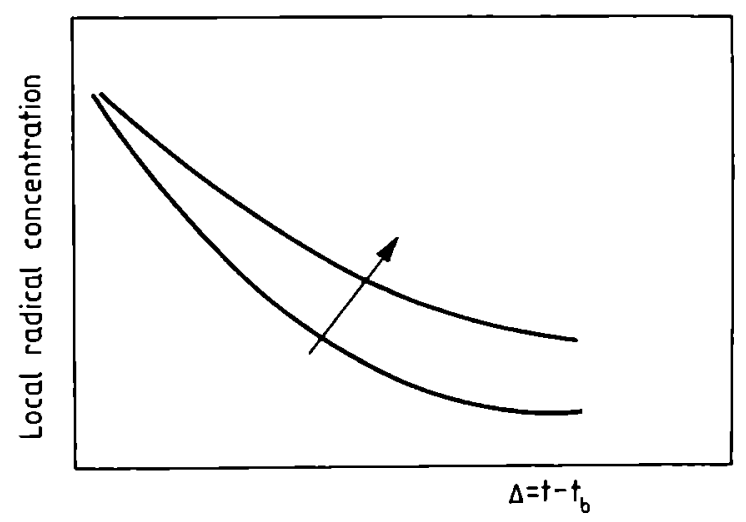

Fig. 5. Local radical concentration versus $\left(t-t_{b}\right)$ [23]

react to form the pendant group birth at time $t_{b}$ ) (Fig. 5) is given by the equation:

$$
\left[\mathrm{P}^{\bullet}\right]_{, \ell_{b},}=\frac{1}{\frac{4}{3} \pi r^{3} N_{A}}
$$

where: $N_{A}$ is the Avogadro number, and $r$ is the radius containing the local radical for a particular pendant group (Fig. 6) given as:

$$
r=r_{c-\mathfrak{c}}+r_{0}
$$

where: $r_{e-c}$ is the average end-to-end distance and $r_{0}$ is the di-

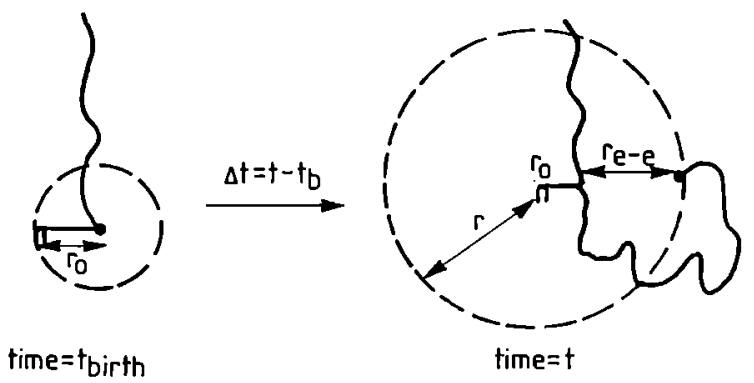

Fig. 6 . The radius containing the local radical for a particular pendant group [23] stance between double bonds. The $r_{v-c}$ is given by the equation:

$$
r_{c-c}=l_{M} \frac{7}{\frac{7}{2}}
$$

where: $l_{M}$ is the effective monomer size and $n_{t, t_{u}}$ is the number of repeat units added since the pendant groups formed and given by the equation:

$$
n_{t, t_{i}}=\int_{t_{p}}^{t_{p}} \eta \mathrm{d} t
$$

where: $\eta$ is the propagation factor.

The rate of the overall consumption for pendant groups consumption $\left(R_{p e n}\right)$ is given as [23]:

$$
R_{p e t h}=k_{p e n t}[P E N]\left[P^{*}\right]+\sum_{t_{n}=0}^{t_{1}=t} k_{c y c}[P E N]_{t, t_{n}}\left[P^{*}\right]_{t, t_{n}}
$$

where: $k_{p e n}$ is the rate constant of pendant groups formation, $\left[P^{*}\right]$ is the concentration of propagating radicals, given as (cf. [1] eqn. (6)):

$$
\left[P^{*}\right]=\left(\frac{f k_{d}[I]}{k_{t}}\right)^{\frac{1}{2}}
$$

where: $f$ is the photoinitiator efficiency, $k_{d}$ and $k_{t}$ are rate constants of the photoinitiator decomposition and termination, respectively, [I] is the photoinitiator concentration; [PEN] is the pendant group concentration in a monomer, $[P E N]_{t, l_{b}}$ (at time that have reacted between the radical ( $\left.R^{*}\right)$ and monomeric double bond that react to form the pendant at time $\left.t_{b}\right), k_{c y c}$ is the rate constant for cyclization, can be assumed to be the same as the rate for propagation:

$$
k_{c y c}=k_{\mu}
$$

however, $k_{\text {cyc }}$ is lower than the $k_{p}$ due to the mobility limitation of pendant groups composed to monomer. The $k_{c y c}$ is by two orders of magnitude lower than the $k_{p}$. This reduction is approximately equivalent to the reduction in the $k_{p}$ of $80 \%$ conversion due to diffusion induced mobility limitations, i.e.:

$$
\mathrm{k}_{c y c}<k_{p}
$$

The complete expression for the local radical concentration $\left(\left[P^{\bullet}\right]\right)_{l, t_{i}}$ is $[23]$ :

$$
\left[P^{*}\right]_{t, t_{b}}=\exp \left(-k_{t}\left[P^{*}\right]\left(t-t_{b}\right)\right) \frac{1}{N_{A}\left(\frac{4}{3} \pi\left(r_{0}+n_{t, l_{b}}^{\frac{1}{2}} l_{M}\right)^{3}\right)}
$$

This calculation assumes a spherical-shaped molecule with the double bonds on the radius.

\section{AUTOACCELERATION OF POLYMERIZATION (GEL EFFECT)}

An autoacceleration process (also known as the gel effect or as the Trommsdorff effect [24]) is observed to occur both in linear and crosslinking polymerizations, due to a decrease of the termination rate constant $\left(k_{t}\right)$ at 
higher monomer conversions $[25,26]$. When the polymer concentrations grow, the macroradicals will become entangled with segments of other polymer chains and formed polymer nets. As a result, the rate of diffusion of the propagating radicals and the frequency of their mutual encounters will decrease, and $k_{t}$ is reduced. In linear polymerization, the decrease of $k_{1}$ occurs slowly at $30-50 \%$ of monomer conversion and then rapidly (at $70-80 \%$ ) [27-30]. The termination process proceeds by two mechanisms: one controlled by segmental diffusion at low conversions (independent of chain length), and another controlled by translational diffusion after the gel effect has started (dependent on chain length) [3, 26, 27, 31, 32]. Rate constants $k_{d}$ and $k_{p}$ are independent from growing propagating radicals at low conversions, and remain constant with concentration, until high concentrations are achieved where the polymerizing system begins to exhibit glassy effects $[33,34]$. The initiator efficiency $(f)$ may change by a factor of $\sim 2$ prior to the onset of the glass effect $[34,35]$. Defining $K$ parameter as:

$$
K=k_{p}\left(\frac{f k_{t}}{k_{\mathrm{r}}}\right)^{\frac{1}{2}}
$$

all of the change in $K$ is due to variation in $k_{f}$ over all the conversion range. Generally, the propagation rate constant $\left(k_{p}\right)$ remains almost constant over a wide conversion range, whereas the termination rate constant $\left(k_{t}\right)$ decreases with conversion showing a plateau at the middle of the conversion region (Fig. 7). In this region, $k_{t}$ be-

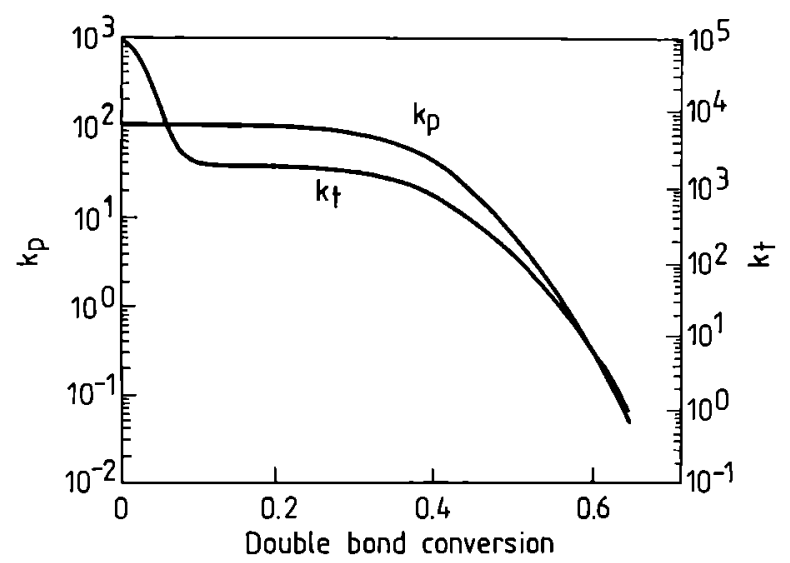

Fig. 7. The characteristic behavior of the propagation $\left(k_{p}\right)$ and termination $\left(k_{1}\right)$ rate constants as a function of double bond conversion for multifunctional monomer crosslinking polymerization [3]

comes proportional to $k_{p}[\mathrm{M}]$ due to the dominance of a reaction diffusion termination mechanism $[26,36]$. Diffusion of very long, entangled chains has a stronger concentration dependence than that of untangled chains. Termination related to the gel effect is not controlled by the chain-end segmental mobility but, instead, is controlled by diffusion of the shortest propagating radical chains. This gives credence to the proposals of "short-long" termination processes [37-39] in which short propagating radical chains control the termination reaction. An approach to this problem is to compare data on the termination rate constant $\left(k_{t}\right)$ with diffusion data in order to determine the type of diffusion control termination $[3,36,40-47]$.

In the crosslinking polymerization $k_{t}$ is strongly dependent on the size of the radicals involved in the termination reaction. The termination reaction is diffusion controlled from the beginning of polymerization and the diffusivity of propagating radicals is dependent on chain length [48-50]. In the crosslinking polymerization termination reactions occur between relatively large propagating radicals entangled in the growing polymer net, and termination rates are limited by the rates at which the radical ends can encounter with each other [51-53]. As a result, $k_{t}$ is a decreasing function of the size of the propagating radical. The segmental diffusion coefficient and the termination rate constant $\left(k_{t}\right)$ increase as the polymer concentration increases from zero.

In the modeling of diffusion controlled kinetics, the polymerization rate constant $\left(k_{\text {prdiff }}\right)$ and the termination rate constant $\left(k_{t(d i f f)}\right)$ which combines a term for the translation/segmental diffusion and the reaction diffusion, are $[51,54]$ :

$$
\begin{aligned}
& k_{p(d i f)}=\frac{1}{\frac{1}{k_{p(\text { Mdiff })}}+\frac{1}{k_{p(\text { clkm })}}} \\
& k_{t(\text { diff })}=k_{t(\text { rmms/sis })}+k_{t(\text { raat })}
\end{aligned}
$$

where: $k_{p(\text { Mdif })}$ is the rate constant for monomer diffusion, $k_{\text {p(chem })}$ is the rate constant for chemical reaction, $k_{1(\text { trrims/scog) }}$ is the termination rate constant for translation/segmental diffusion, and $k_{\text {trenct) }}$ is the termination rate constant for reaction diffusion.

The $k_{t(d i f)}$ for crosslinked polymerization can be derived from Smoluchowski's equation for the prediction of diffusion controlled bimolecular rate coefficients [55] and Einstein's relation between the diffusion coefficient and the frequency of propagation $[8,56,57]$ :

$$
k_{t(\mathrm{dif})}=\frac{4 \pi}{3} \xi a^{2} r_{n} k_{p}[\mathrm{M}]
$$

where: $\xi$ is the probability of reaction when two radicals come within the capture distance of each other, $a$ is the root-mean-square end-to-end distance per square root of the number of monomer units, and $r_{1}$ is the radius of interaction at two extremes:

- at rigid limit: the chain end cannot move on the time scale of propagation, and thus, the radius of interaction is half the diameter of monomer $(\sigma / 2)$,

- at flexible limit: the radius of interaction is approximated as $j^{1 / 2}$, where $j$ is the distance between entanglements [58].

The parameter $\xi$ has values between 0 and 1 due to the effects of spin multiplicity and steric hindrance $(\xi=$ 
1 at high conversion, $\xi=0.25$ at low conversion, and $\xi=$ 0 in sterically hindered systems) [57, 59].

Two diffusion controlled termination rates, minimum $\left(R_{t(d i f) \min }\right)$ and maximum $\left(R_{t(d i f f) \max }\right)$, are given by the equations $[35,46,56]$ :

$$
\begin{aligned}
& R_{t(\text { diff } f) \min }=\frac{k_{l(d i f f) \min }}{k_{p}[M]}=\frac{2 \pi}{3} \xi a^{2} \sigma \\
& R_{l(\text { diff })_{\text {max }}}=\frac{k_{t(d i f) \max }}{k_{p}[M]}=\frac{4 \pi}{3} \xi a^{3} j^{\frac{1}{2}}
\end{aligned}
$$

$R_{t(\text { dif })}$ for acrylates is 3-5 liter $\cdot \mathrm{mol}^{-1}$ [38] and for methacrylates is 2 liter $\cdot \mathrm{mol}^{-1}$ [41]. The ratio of:

$$
R_{t(\text { diff })}=\frac{R_{t(\text { diff }) \text { max }}}{R_{t(d i f f) \text { min }}}=2 a \frac{j^{\frac{1}{2}}}{\sigma}
$$

Since the ratio $(a / \sigma)$ is of the order of 1 and $j$ approaches 1 as the crosslinking density increases, $R_{\text {t(dif) }}$ approaches 2 for a highly crosslinked polymer matrix [46]. For a loosely crosslinked network, polymerized above the glass transition temperature $\left(T_{g}\right), R_{t(d i f)}$ should approach the flexible limit, i.e. $R_{t(d i f) m a x}$, because the distance from the last attachment to the network is significantly larger, and the overall mobility of the system is increased by polymerizing above $T_{g}$. As the polymerization temperature is lowered below $T_{g^{\prime}}$ the distance back to the last network attachment point or entanglement becomes less important, and the mobility of the radical chain end is reduced to the point where it is virtually immobile on the time scale of propagation. In this case, the rigid limit should be applicable, and $R_{l(d i f f)}$ should approach $R_{t(d i f) \min }$ just as it would for a highly crosslinked network [46].

Deviations resulting from the diffusion control of termination at low conversion of monomer $(<1-2 \%)$ to polymer are negligible. However, changes in the reaction rate resulting from hindered diffusion at high conversions are very important in the crosslinking polymerization. The rate of polymerization $\left(R_{p}\right)$ decreases gradually as the reaction proceeds and the concentration of monomer and the initiator are depleted.

Termination reactions are also influenced by the viscosity of the reaction medium. The termination rate constant $\left(k_{l}\right)$ is inversely proportional to the viscosity of the reaction medium from zero conversion [60,61], and the $k_{1}$ may not remain constant even at a very low conversion range $[62,63]$. A model has been proposed that accounts for these variations in $k_{t}$ in a low-conversion radical polymerization $[64,65]$.

The rate of propagation $\left(R_{p}\right)$ is affected much less than the rate of termination. The propagation reaction involves the reaction of a large radical with a small monomer whose diffusion rate is not changed significantly, whereas the termination process involves two macroradicals whose ends have reduced mobility, because motion of their centers of mass has become restrained. The net result in this case is an increase in the effective $k_{p} / k_{t}^{1 / 2}$ ratio and an increase in the rate of polymerization.

Kinetic free volume model predictions of rate constant $k_{p}$ and $k_{t}$ on segmental diffusion controls, assume that they are proportional to the diffusion coefficients of the reacting species for values below a critical diffusion coefficient $[66,67]$. Rate constants $k_{p}$ and $k_{t}$ are proportional to the diffusion coefficients of monomer $\left(D_{M}\right)$ and polymer propagating radical $\left(D_{p}\right.$. $)$ in the polymerizing system, respectively:

$$
\begin{aligned}
& k_{p} \propto D_{M} \text { for } D_{M}<D_{M(\text { crit })} \\
& k_{\ell} \propto D_{p} . \text { for } D_{p}<D_{P^{*}(\text { crit })}
\end{aligned}
$$

where: $D_{M(c r i)}$ and $D_{p^{\cdot}(\text { crit })}$ are critical diffusion coefficients corresponding to the onset of the diffusion controlled region.

The $D_{M}$ and $D_{p}$. diffusion coefficients can be determined from the fractional free volume $\left(v_{f}\right)$ of the monomer-propagating radical from the following equations:

$$
\begin{gathered}
D_{M}=\frac{v \vartheta^{2}}{6} \exp \left(-\frac{B}{v_{f}}\right) \\
D_{P^{*}}=\frac{v \vartheta^{2}}{C} M_{W} \exp \left(-\frac{A}{v_{f}}\right)
\end{gathered}
$$

where: $v$ is the jump frequency, $\vartheta$ is the jump distance, $M_{W}$ is the molecular weight of a monodisperse polymer, $A, B, C$ are constants.

The proportionality constants from eqs. (17) and (18), and the preexponential factors in eqns. (19) and (20) can be eliminated by letting $k_{p}=k_{p(0)}$ and $k_{t}=k_{1(0)}$ at the critical fractional free volume for propagation $v_{f(c r i t)}$ :

$$
\begin{gathered}
k_{p}=k_{p(0)} \exp \left[-A\left(\frac{1}{v_{f}}-\frac{1}{v_{f p(\text { crit })}}\right)\right] \\
k_{1}=k_{t(0)}\left(\frac{M_{w}}{M_{w(c r i t)}}\right) \exp \left[-B\left(\frac{1}{v_{f}}-\frac{1}{v_{f(\text { crit })}}\right)\right]
\end{gathered}
$$

where: $M_{W}$ is the molecular weight of a monodisperse polymer, $M_{w(c r i)}$ is the molecular weight at the point the reaction becomes diffusion controlled, $v_{f(c r i)}$ and $v_{\text {ftcrit }}$ are the fractional free volumes at the onset of the diffusion-control region for propagation and termination, respectively.

For the development of this model it was assumed that segmental diffusion controls the $k_{p}$ and $k_{t}$ and that there is no dependence of $k_{t}$ on $M_{w}$, i.e. $\alpha=0$. In order to apply the free-volume model, it is essential to determine the equilibrium fractional free volumes as a function of conversion [66].

In the kinetics of the crosslinking polymerizations for some of polymerizing formulations are observed double maxima in the rate of polymerization [54, 68-70] (Fig. $8 a, b)$. The first peak can be attributed to the Trommsdorff effect for the growing polymer matrix while it is still homogeneous, and the second peak occurs due to the Trommsdorff propagation rate acceleration in micro- 

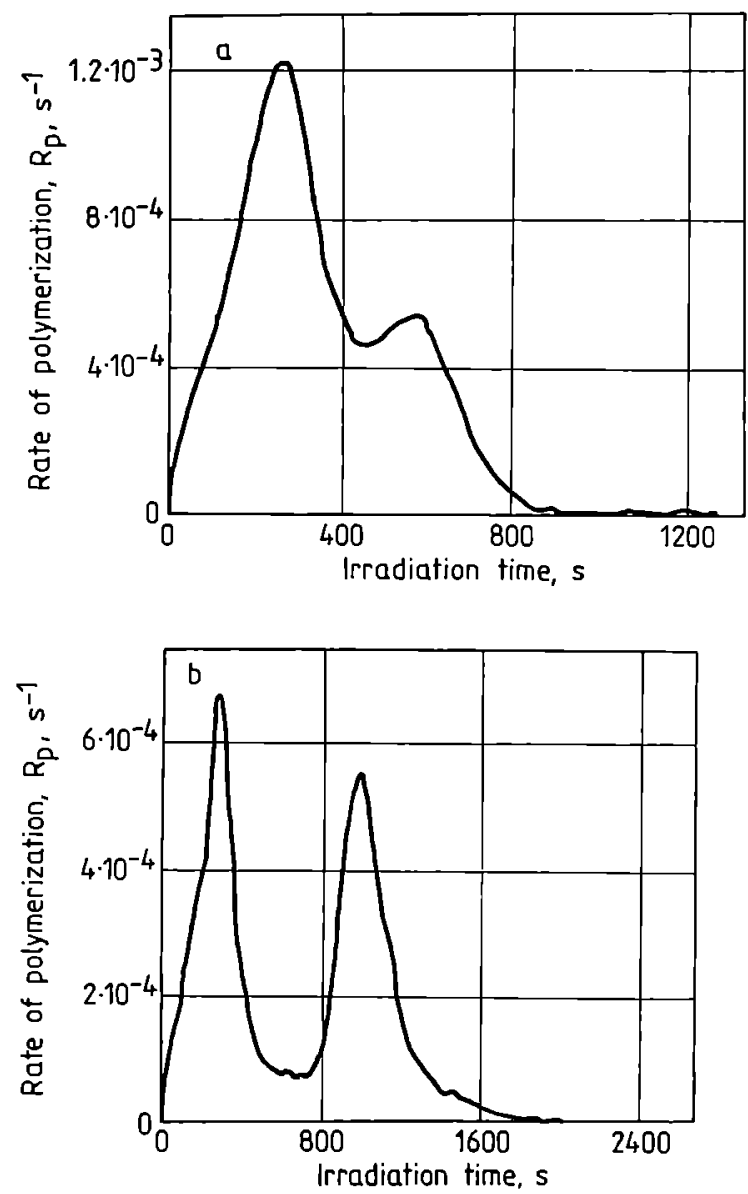

Fig. 8. Two rates of polymerization of: (a) triethylene glycol dimethacrylate (TEGDM) and (b) TEGDM and poly(acrylic acid), both in air [71, 72]

gels [68]. Another explanation of the two peak maxima observed in photopolymerization in air was proposed on the basis of different reactivities of propagating radicals and peroxy and oxy radicals [69, 71-75]:

$$
\begin{gathered}
\mathrm{P}^{*}+\mathrm{O}_{2} \longrightarrow \mathrm{POO}^{*} \\
\mathrm{POO}^{*}+\mathrm{PH} \longrightarrow \mathrm{POOH}+\mathrm{P}^{\cdot}
\end{gathered}
$$

Very reactive oxy $\left(\mathrm{PO}^{\circ}\right)$ radicals are formed by thermal decomposition of hydroperoxy groups $(\mathrm{POOH})$ by the heat of polymerization $(\Delta)$ :

$$
\mathrm{POOH} \stackrel{\Delta}{\longrightarrow} \mathrm{PO}^{*}+{ }^{\circ} \mathrm{OH}
$$

In a number of photopolymerizations there is observed a postcure effect, which is a light-independent polymerization occurring after light has been switched off. The postcure effect can be explained by that the residual unreacted initiator generates sufficient amounts of radicals to promote crosslinking regardless of the greater immobility of the network.

\section{MODELING OF OVERALL RATE OF POLYMERIZATION}

Modeling of the overall rate of polymerization (initiation, propagation and termination) requires an accurate reaction kinetic model to predict the rate of polymerization at a given temperature and conversion. The kinetic model should predict:

- photoinitiator concentration and efficiency, mechanism and kinetics of a photoinitiator decomposition into free radicals, radicals reactivity and selectivity in the initiation of propagation, inhibitor concentration and kinetics of inhibition, the effect of temperature;

- the acceleration and deceleration of propagation reaction due to gel effect and diffusion limitations;

- termination of propagation due to recombination reactions, chain transfer and trapping of propagation radicals in a polymer matrix;

- the kinetics of conversion and final extent of cure;

- volume contraction (shrinkage).

Several models have been developed to describe autoacceleration in the absence of a significant delay in volume shrinkage for linear polymerization [76-81].

The following equations have been used for modeling the linear polymerization with $V$ as system volume [25]:

$$
\begin{gathered}
\frac{1}{V} \frac{\mathrm{d}[M V]}{\mathrm{d} t}=-k_{\mu}[M] \sum_{\mu=1}^{\infty}\left[P^{*}\right]_{\mu} \\
\frac{1}{V} \frac{\mathrm{d}\left[R^{*} V\right]}{\mathrm{d} t}=2 f k_{d}[I]-k_{t}[M]\left[R^{*}\right] \\
\frac{1}{V} \frac{\mathrm{d}[I V]}{\mathrm{d} t}=-k_{d}[I]
\end{gathered}
$$

$\frac{1}{V} \frac{\mathrm{d}\left[P^{*} V\right]_{n=1}}{\mathrm{~d} t}=k_{i}[M]\left[R^{*}\right]-k_{p}[M]\left[P^{*}\right]_{n=1}-\left[P^{*}\right]_{n=1} \sum_{n=1}^{\infty} k_{r}\left[P^{*}\right]_{n}$

$$
\frac{1}{V} \frac{\mathrm{d}\left[P^{*} V\right]_{n}}{\mathrm{~d} t}=-k_{p}[M]\left(\left[P^{*}\right]_{n-1}-\left[P^{*}\right]_{n}\right)-\left[P^{*}\right]_{n} \sum_{j=1}^{\infty} k_{t}\left[P^{*}\right]_{j}
$$

where: [I] and [M] are concentrations of initiator and monomer, respectively, $\left[R^{*}\right]$ is the concentration of radicals from the initiator decomposition, $\left[P^{*}\right]_{n}$ is the concentration of the propagating radical of length $n$, $f$ is the initiator efficiency, $k_{d}$ $k_{i}$ and $k_{p}$ are rate constants of initiator decomposition, initiation of polymerization, and propagation, respectively, and $t$ is the polymerization time.

For further modeling, eqns. (30) and (31) can be reduced to [85]:

$$
\begin{gathered}
\frac{\mathrm{d}[I]}{\mathrm{d} t}=-k_{d}[I] \frac{\varpi[I]}{1+\varpi p}(1-p) k_{p} \sum_{n=1}^{\infty}\left[P^{*}\right]_{n} \\
\frac{\mathrm{d} p}{\mathrm{~d} t}=k_{p}(1-p) \sum_{n=1}^{\infty}\left[P^{*}\right]_{n} \\
\frac{\mathrm{d} \sum_{n=1}^{\infty}\left[P^{*}\right]_{n}}{\mathrm{~d} t}=-\frac{\left(\sum_{n=1}^{\infty}\left[P^{*}\right]_{n}\right)^{2}}{1+\varpi p}(1-p) k_{p}+2 f k_{d}[I]-k_{t}\left(\sum_{n=1}^{\infty}\left[P^{*}\right]_{n}\right)^{2}
\end{gathered}
$$

where: $\omega$ is a volume contraction factor defined as:

$$
\varpi=\frac{d_{M}-d_{P}}{p}
$$

where: $d_{M}$ and $d_{p}$ are monomer and polymer densities, respectively, and $p$ is the fractional monomer conversion. 
With appropriate information about the initial values of the rate parameters and their dependencies on system conditions, eqns. (32-33) can be solved simultaneously by using numerical techniques to provide predicted conversion-time results.

The rate of polymerization is difficult to model because of the competing reactions between several photoinitiators, inhibitors, and comonomers [82, 83], changing initiator efficiency [84], effects of free volume [26, 66, 85, 86], homegeneities during network formation [87], entanglements [88], substitution effects [89-91], diffusion limitations [83, 84, 92-94], gel inhomogeneities before gel point $[92,96]$, reactions between microgel particles after the gel point [97], simultaneous crosslinking and scission reactions [98], and a delay in volume shrinkage and incomplete conversion of reactive groups [2].

Assumption of a steady state is valid only for linear polymerization of monofunctional monomers and polymerization in solution; however, it does not apply to the photocrosslinked polymerization [66]. The reason is that the low mobility of propagating radicals causes that termination by radical recombination is not a significant factor as in the case of conventional polymerization of monofunctional monomers. The analytical solution of the kinetic equations becomes difficult in the absence of the steady-state condition. Much effort has been spent in order to model crosslinking polymerization through $[3,99]$ :

- statistical approach, whereby polymer structures evolve according to certain probabilistic rules for the formation of bonds between smaller monomer molecules [100-107].

- kinetically based approach, which involves solving the differential equations that describe the concentration of each reacting species [67, 108-115].

- structure simulation approach, which involves simulation of the structure in space using a percolation type simulation called the kinetic gelation model $[9,116-123]$.

\section{RATE OF POLYMERIZATION IN THE PHOTOINDUCED ELECTRON/PROTON TRANSFER (EPT) MECHANISM}

Donor radicals $\left(\mathrm{D}^{*}\right)$ formed in the reaction [eqn. (35)] (cf. [75], eqn. (53)):

$$
\mathrm{I}^{*}+\mathrm{DH} \longrightarrow \mathrm{IH}^{*}+\mathrm{D}^{*}
$$

where: $I$ is the initiator and $D H$ is the donor molecule.

The donor radical $\left(D^{*}\right)$ initiates polymerization reaction:

$$
\mathrm{D}^{*}+\mathrm{M} \longrightarrow \mathrm{P}^{*}
$$

The rate of polymerization $\left(R_{p}\right)$ for the bimolecular reaction [36] is given by:

$$
R_{p}=-\frac{\mathrm{d}[M]}{\mathrm{d} t}=\frac{k_{p}}{k_{l}^{\frac{1}{2}}} \cdot[M] \cdot\left[D^{*}\right]
$$

With the steady state assumed to occur, the rate of donor radicals $\left(D^{*}\right)$ production is equal to the rate of radicals $\mathrm{D}^{*}$ termination by the combination process:

$$
R_{D_{\bullet}}=R_{t c} \text { at steady state conditions }
$$

Substituting eqns. (40) (cf. [75], eqn. (57))

$$
R_{D^{*}}=\frac{\mathrm{d}\left[D^{*}\right]}{\mathrm{d} t}=k_{\mathrm{cl}} I_{n} \cdot[D H]
$$

where (cf. [75], eqn. (16))

$$
I_{n}=I_{0} \varepsilon[\mathrm{I}] l
$$

where: $I_{n}$ is the intensity of the light absorbed, $I_{0}$ is the intensity of incident light, $\varepsilon$ is the molar extinction and $l$ is the path length, and eqn. (42) (cf. [75], eqn. (70))

$$
R_{t c}=2 k_{t c}\left[\mathrm{D}^{*}\right]^{2}
$$

into eqn. (39) gives

$$
k_{t l} I_{n}[\mathrm{DH}]=2 k_{t c}\left[\mathrm{D}^{*}\right]^{2}
$$

where: $k_{t c}$ is the rate of termination of radicals $D^{*}$ by the recombination reactions:

$$
\begin{aligned}
& D^{*}+D^{\cdot} \stackrel{k_{t+1} \longrightarrow}{\longrightarrow} \text { inactive products } \\
& D^{\cdot}+M^{*} \stackrel{k_{t+2} \longrightarrow}{\longrightarrow} \text { inactive products }
\end{aligned}
$$

The overall termination rate constant by recombination is:

$$
k_{t c}=k_{t c 1}+k_{t c 2}
$$

and

$$
\left[D^{*}\right]=\left(\frac{k_{c l} I_{a}[D H]}{2 k_{t c}}\right)^{\frac{1}{2}}
$$

Substituting eqn. (46) into eqn. (37), the rate of polymerization $\left(R_{p}\right)$ is

$$
R_{p}=-\frac{\mathrm{d}[M]}{\mathrm{d} t}=\frac{k_{p}}{k_{1}^{\frac{1}{2}}} \cdot[M]\left(\frac{k_{c l} I_{a}[D H]}{2 k_{t c}}\right)^{\frac{1}{2}}
$$

Combination of eqn. (48) (cf. [75], eqn. (37)):

$$
k_{\mathrm{rl}}=\kappa Z \exp \left(\frac{-\Delta G \#}{R T}\right)
$$

where: $\kappa$ is the electronic transition coefficient, $Z$ is the nuclear frequency factor, $\Delta G \#$ is the free energy of activation, and eqn. (49) (cf. [75], eqn. (38)):

$$
\Delta G \#=\frac{\lambda}{4}\left(1+\frac{\Delta G^{0}}{\lambda}\right)^{2}
$$

where: $\lambda$ is the reorganization energy and $\Delta G^{0}$ is the free enthalpy, with eqn. (47) gives:

$$
R_{p}=\frac{k_{p}}{k_{t}^{\frac{1}{2}}} \cdot[M]\left[\kappa \dot{Z} \exp \left(\frac{-\frac{\lambda}{4} \cdot\left(1+\frac{\Delta G^{0}}{\lambda}\right)}{R T}\right)^{2} \frac{I_{n}[D H]}{2 k_{t c}}\right]^{\frac{1}{2}}
$$


Equation (50) shows that the rate of polymerization $\left(R_{p}\right)$ in the EPT process depends on the thermodynamical parameter $\Delta G^{0}$. The rate constant of polymerization $\left(R_{p}\right)$ should increase with decreasing $\Delta G^{0}$ at relatively high values of $\Delta G^{0}$, whereas it should decrease with increasing $\Delta G^{0}$ at low values of $\Delta G^{0}$ (i.e., $\Delta G^{0}$ is negative and large). The region where $R_{p}$ decreases with decreasing $\Delta G^{0}$ is called the Marcus "Inverted Region". The parabolic (bell) shape of the Marcus plot (Fig. 9) shows that the $R_{p}$ depends considerably on the structure of hy-

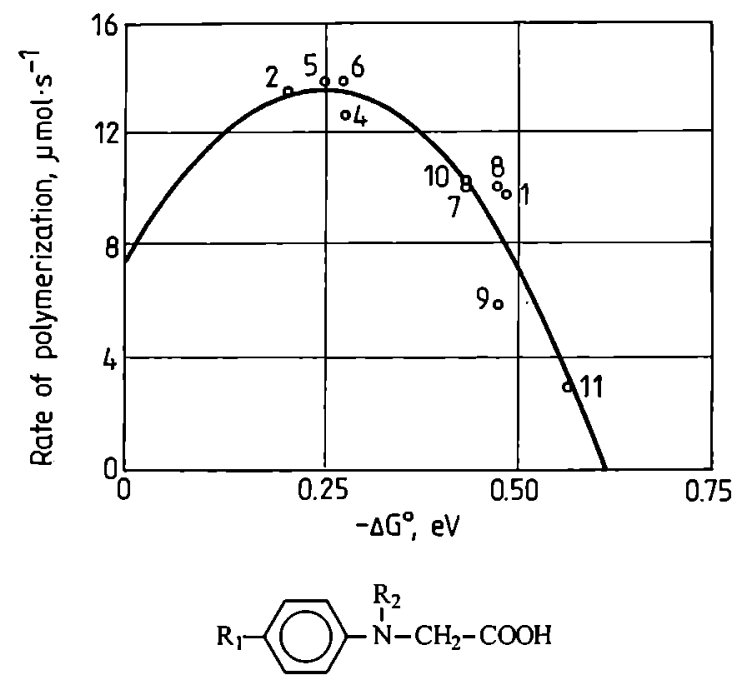

\begin{tabular}{|c|c|c|c|c|}
\hline No. & $\begin{array}{c}N \text {-substi- } \\
\text { tuent } \mathrm{R}_{2}\end{array}$ & $\begin{array}{l}p \text {-substi- } \\
\text { tuent } R_{1}\end{array}$ & $\mathrm{E}_{\mathrm{ox}}, \mathrm{mV}$ & $\Delta G^{0}, e V$ \\
\hline 1 & $\mathrm{H}$ & $\mathrm{H}$ & 426 & -0.485 \\
\hline 2 & $\mathrm{H}$ & NO & 707 & -0.204 \\
\hline 3 & $\mathrm{H}$ & $\mathrm{NO}_{2}$ & 781 & $-0,130$ \\
\hline 4 & $\mathrm{H}$ & $\mathrm{H}_{3} \mathrm{C}-\mathrm{O}$ & 635 & $-0,276$ \\
\hline 5 & $\mathrm{H}$ & $\mathrm{Ph}-\stackrel{\mathrm{O}}{\mathrm{C}}$ & 661 & $-0,250$ \\
\hline 6 & $\mathrm{H}$ & O & 639 & $-0,276$ \\
\hline 7 & $\mathrm{H}$ & $\mathrm{Cl}$ & 479 & $-0,432$ \\
\hline 8 & $\mathrm{H}$ & $\mathrm{CH}_{3}$, butyl & 437 & $-0,474$ \\
\hline 9 & $\mathrm{H}$ & tert-Bu & 436 & $-0,475$ \\
\hline 10 & $\mathrm{H}$ & $\mathrm{PhO}$ & 479 & $-0,432$ \\
\hline 11 & $\mathrm{H}$ & $\mathrm{MeO}$ & 343 & $-0,568$ \\
\hline
\end{tabular}

Fig. 9. Rate of polymerization $\left(R_{p}\right)$ as a function of the free energy of activation $\left(\Delta G^{0}\right)$ for camphorquinone (I) and differently substituted $N$-phenyl glycines $(1-10)$ (results give the Marcus parabolic relation) [124] drogen atom donors (DH), i.e., on their oxidation potentials $\left(E_{o x}\left(\mathrm{DH} / \mathrm{DH}^{-+}\right)\right.$. The $R_{p}$ values calculated from eqn. (50) are valid only for linear polymerization, because of the steady state assumption. Nevertheless, this kinetics has been applied to crosslinking photopolymerization [124].

\section{KINETIC TREATMENT OF PHOTOPOLYMERIZATION BY PHOTO-DIFFERENTIAL (ISOTHERMAL) SCANNING CALORIMETRY}

Photo-differential (isothermal) scanning calorimetry (photo-DSC) has been extensively used for the study of crosslinking photopolymerization [125, 126]. An isothermal DSC trace is a plot of the heat evolved in polymerization reaction against the time of reaction; it allows to determine several kinetic parameters (Fig. 10): the rate

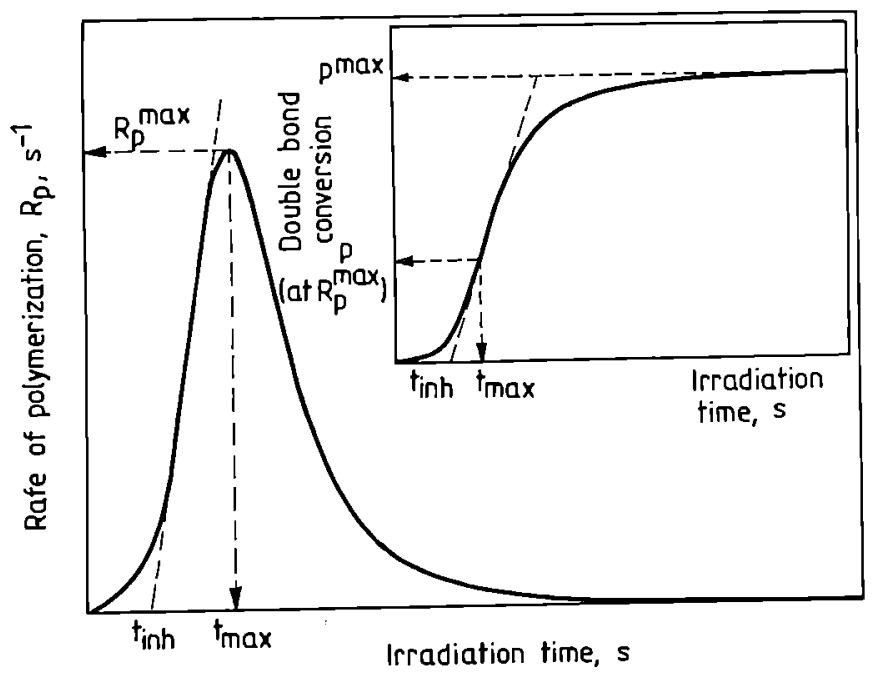

Fig. 10. Typical DSC photopolymerization profiles and indications of the: rate of polymerization $\left(R_{p}\right.$ and $\left.R_{p}{ }^{\max }\right)$, time to reach the maximum rate of polymerization $\left(t_{\max }\right)$, inhibition time $\left(t_{\text {inil }}\right)$ (from the slope of kinetic curve crossing the coordination of irradiation), double bond conversion $(p)$, its ma$\operatorname{ximum}\left(p_{\max }\right)$ and $p$ at $R_{p}^{\max }$

of polymerization $\left(R_{p}\right)$, the maximum rate of polymerization $\left(R_{p}{ }^{m a x}\right)$, the double bond conversion $(p)$, the highest degree of double bond conversion $\left(p^{m a x}\right)$, the time in which $R_{p}^{m a x}$ appears $\left(t_{\max }\right)$, inhibition time $\left(t_{\text {int }}\right), R_{p}$ versus p (Fig. 11), inhibition and retardation kinetics (Fig. 12), reaction order, activation energy, and Arrhenius preexponential factor. A most general treatment of thermoanalytical kinetic data gives very condensed accounts of the isothermal DSC method [127]. The fact that typical photo DSC samples $(\approx 1 \mathrm{mg})$ are around 80 microns thick led to one of the biggest problems in the methodi- 


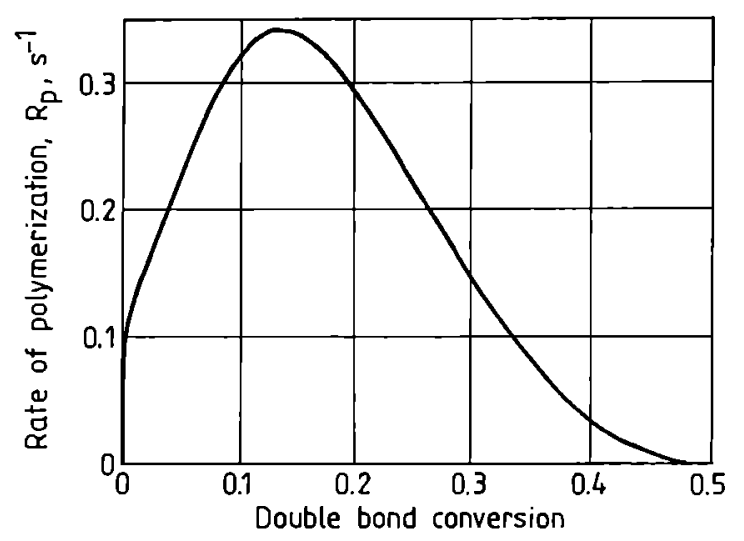

Fig. 11. A typical rate of polymerization $\left(R_{p}\right)$ versus conversion of double bonds conversion ( $p$ )

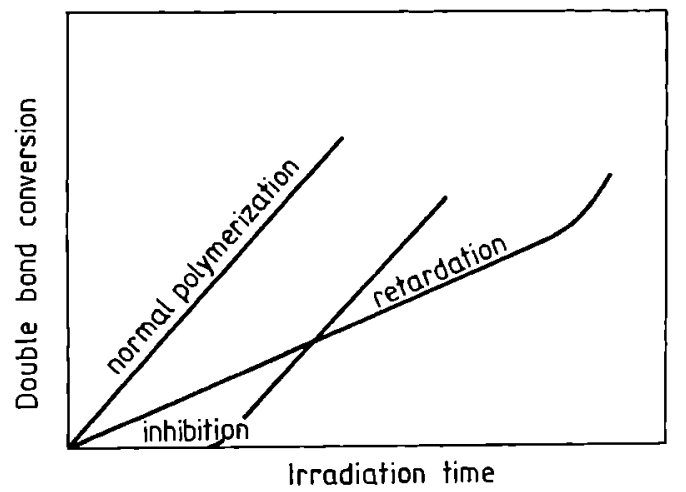

Fig. 12. Conversion versus time plots for normal, retarded and inhibited polymerizations

cal development of this technique, the extent of light absorption through the sample. This film thickness makes photo DSC well-suited to the study of propagation kinetics in thin films but far removed from the conditions of kinetics polymerization in the bulk. The self-screening (cf. [75]) that occurs in the samples also shows itself as an exotherm distortion [128]. The isothermal DSC trace is distorted to have a steep leading edge (indicative of the very fast photopolymerization at the sample surface), and a long trailing back edge (indicative of the low probability of light absorption by the photoinitiating system near the bottom of the sample).

The instantaneous heat release $\left(\Delta H_{t}\right)$ at a given time $(t)$, (the DSC ordinate y) at time $t$ is proportional to the rate of polymerization $\left(R_{p}\right)$ at that time $t$, i.e., to $-\mathrm{d}[\mathrm{M}] / \mathrm{dt}$ :

$$
R_{p}=-\frac{\mathrm{d}[M]_{t}}{\mathrm{~d} t}=\frac{\frac{\mathrm{d} \Delta H_{t}}{\mathrm{~d} t}}{n \Delta H_{0}[M]}
$$

where: $\Delta H_{0}$ is the theoretical enthalpy of polymerization, and $n$ is the number of double bonds present in a monomer; e.g., $\left(\Delta H_{0}=57800 \mathrm{~J} \cdot \mathrm{mol}^{-1}\right.$ for the methacrylate group [129]).
Considering the Avrami rate law [130-132], the rate of polymerization $\left(R_{p}\right)$ can be presented as

$$
\begin{gathered}
R_{p}=-\frac{\mathrm{d}[M]_{t}}{\mathrm{~d} t}=k_{p}[M]_{t}^{t} \\
R_{p}=-\frac{\mathrm{d}[M]_{t}}{\mathrm{~d} t}=k_{\mu}[M]_{t}^{\prime \prime}[P]_{t}^{\prime \prime}
\end{gathered}
$$

where: $P$ is the dead polymer, and $n$ and $m$ are integers.

Writing:

$$
[M]_{t}=\left[M b_{b}(1-\alpha)\right.
$$

where: $\alpha$ is the fraction of $M$ reacted at time $t$, eqn. (53) becomes:

$$
R_{\nu}=\frac{-\mathrm{d}[M]_{t}}{\mathrm{~d} t}=[M]_{0} \frac{\mathrm{d} \alpha}{\mathrm{d} t}=k_{p}[M]_{0}^{\prime \prime}(1-\alpha)^{n}
$$

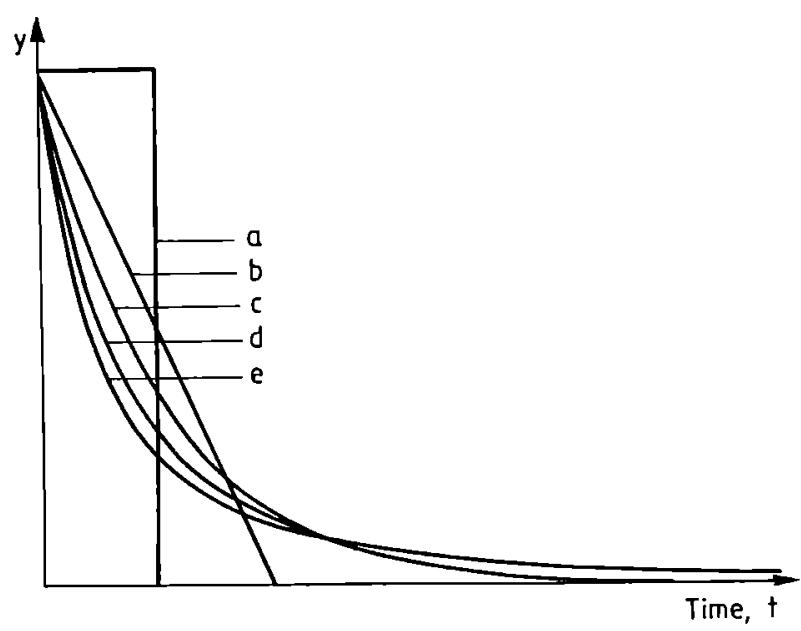

Fig. 13. Kinetic curves for reactions conforming to eqn. (52), for: (a) $n=0$, (b) $n=1 / 2$, (c) $n=1$, (d) $n=3 / 2$ and (e) $n$ $=2[133]$

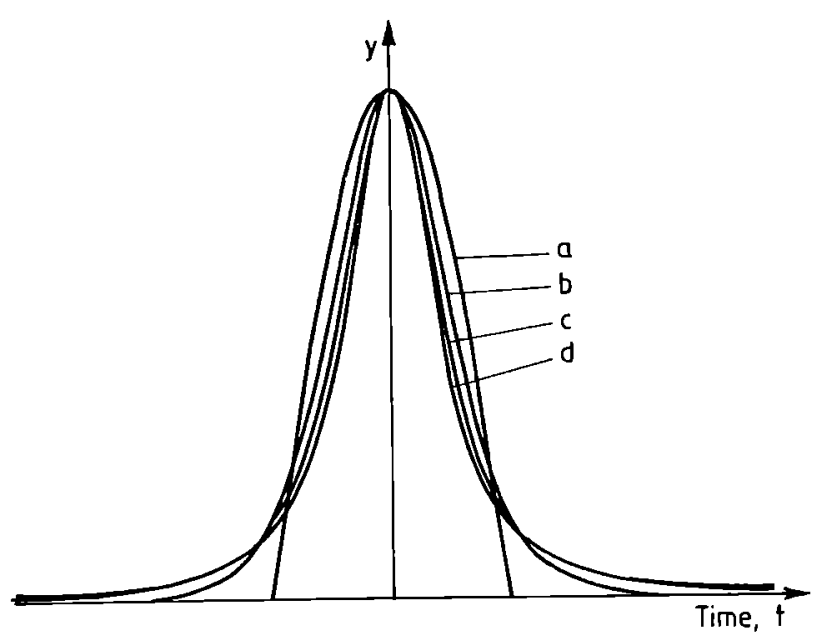

Fig. 14. Kinetic curves for reactions conforming to eqn. (53), for: (a) $n=m=1 / 2$, (b) $n=m=1$, (c) $n=m=3 / 2$ and (d) $n=m=2$ [133] 


$$
\frac{\mathrm{d} \alpha}{\mathrm{d} t}=f(\alpha)=k_{p}\left[M_{b}^{r-1}(1-\alpha)^{n}\right.
$$

Modeling these equations with $n=0, n=m=1 / 2,1$, $3 / 2$ and 2, gives the kinetic curves shown in Fig. 13 and Fig. 14 [133].

\section{REACTIVITIES OF RADICALS AND MONOMERS}

Reactivities of various radicals are usually assessed by comparing the rate constants for selected reactions. This is not a convenient procedure in free-radical crosslinking polymerization, because absolute rate constant measurements are still not available. However, the relative reactivities of various monomers towards a given radical can be computed from the reciprocals of the reactivity ratios. It is not possible to conclude that $R_{1}{ }^{\circ}$ will always react $x$ times more rapidly than radical $R_{2}{ }^{\circ}$ in addition reactions or $y$ times as rapidly in the hydrogen-atom absorption reactions. This is because resonance, steric, and polar influences all come into play and their effects can depend on the particular species involved in a reaction. Understanding of how resonance, steric, polar and electronic factors influence radical-monomer reaction rates is far from complete [134, 135].

The controlling factor in the reactivity of a given monomer is the stability of the radical $\left(\mathrm{P}^{*}\right)$ formed by addition of the monomer $(\mathrm{M})$ to the initial radical $\left(\mathrm{R}^{\circ}\right)$. Monomers that yield radicals in which the unpaired electron is extensively delocalized have ground state structures that are themselves resonance stabilized. The important factor is the relative stability of the radical $\left(\mathrm{P}^{*}\right)$, because a single unpaired electron is more easily delocalized than one in the $\mathrm{C}=\mathrm{C}$ double bond. Thus, the resonance stabilization causes an increase in monomer reactivity and a decrease in the reactivity of the propagating polymer radical.

Free radicals formed from photoinitiators by $\alpha$-photocleavage [75] and by hydrogen-atom transfer [75] and multifunctional monomers are neutral, but variations in the reactivities of all these species can be rationalized and predicted by considering that the transition states in their reactions may have some polar effects. Appropriate substituents may facilitate or hinder a particular reaction because of their influence on the polarity of the reaction site.

The effect of substituents on the relative radical efficiency $(f)[136]$ is expressed by the Hammett equation [137, 138]:

$$
\frac{f}{f_{0}}=\rho \sigma+R+E_{s}
$$

where: $f$ and $f_{0}$ are radical efficiency with a substituent $S$ in place, and reference radical with hydrogen atom as a substituent at the same position, respectively; $\rho$ is the substituent constant and is a measure of the electronic effect of the substituent $S$ at the particular position; $\sigma$ is the reaction constant which measures the sensitivity of the reaction to the electronic effect of a substituent at a particular position in the molecular framework; $R$ and $E_{s}$ are resonance and steric effects, respectively.

The resonance $(R)$ and steric effect $\left(E_{s}\right)$ can be neglected. If a plot of $\log \left(f / f_{0}\right)$ versus $\sigma($ at $\sigma=1)$ gives a straight line which passes through the origin $(0,0)$, a linear Hammett correlation is obtained (Fig. 15). A linear correlation tells us that the radical efficiency is affected in a consistent way by the electron donating or withdrawing ability of substituents $(S)$. A positive $\rho$ means that the radical efficiency increases with electron withdra-

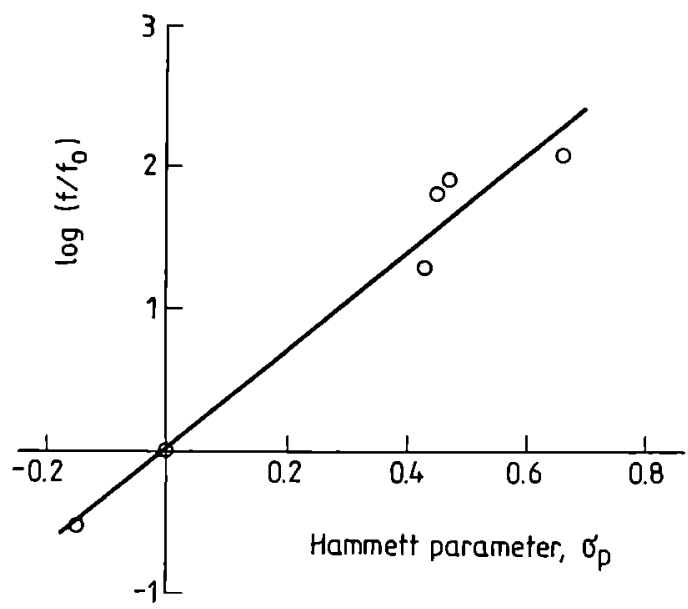

Fig. 15. Plot of relative radical reactivity $\left[\log \left(f / f_{0}\right)\right]$ versus Hammett substituent parameter $(\sigma)$ [138]

wing substituents. Conversely, a negative $\rho$ indicates that the radical efficiency is favored by electron donating substituents [138].

The effects of substituents on the reactions on phenyl rings permit the assignment of nucleophilic (electron-releasing) character to various groups [138]. These include alkyls, vinyl, hydroxyl, ether, phenyl and ester groups. Electrophilic (electron withdrawing) substituents include halogen, nitro, cyanide, carboxyl, and carbonyl groups. Steric influences may also retard some radical polymerizations.

Kinetic model predictions of monomer reactivity can be evaluated on the monomer mobility [123]. The reactivity (R) of pendant functional groups to monomeric functional groups can be determined as [123]:

$$
R=\frac{2[M]}{[P]}\left(1+\frac{\mathrm{d}[\mathrm{P}]}{\mathrm{d}[\mathrm{M}]}\right)
$$

where: $[M]$ is the concentration of monomeric functional groups and $[P]$ is the concentration of pendant functional groups.

Values of $[\mathrm{M}]$ and $[\mathrm{P}]$ can be obtained from simulations and then the derivative is calculated numerically. The results indicate that, early in the reaction, i.e., below 
$25 \%$ conversion, the reactivity of the pendant functional group is significantly higher than that of the monomeric functional group. This is expected as pendant functional groups exist only in the local region around the active radical and are, therefore, much more likely to react with it. As the reaction proceeds to higher conversions, pendant functional groups become imbedded and trapped within the polymer matrix, inaccessible to the active radicals. This tendency decreases the effective concentration of pendant functional groups and hence decreases the reactivity above a conversion of approximately $70 \%$, beyond which the reactivity ratio falls below 1.0. The imbedding of functional groups, both monomeric and pendant, within the polymer leads to the attainment of a maximum conversion despite the presence of continuing initiation (Fig. 16).
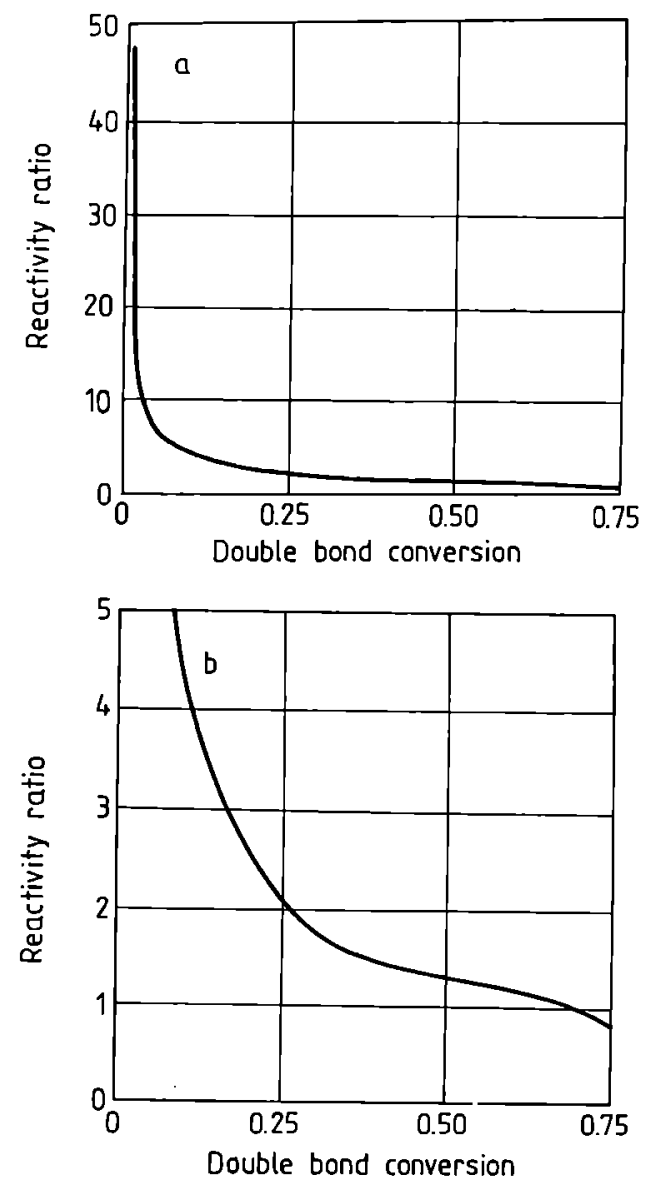

Fig. 16. The reactivity ratio as a function of conversion: (a) a complete range of reactivity ratios, (b) an expansion of the lower reactivity ratio regime [123]

Studies of the reactivities of different multifunctional monomers are the subject of several publications [54, 125]. For example, the rate of photopolymerization of triacrylates is higher than that of diacrylates (Fig. 17) [125], and that of dimethacrylates higher than that of diacrylates [51]. This trend is as expected because an increase in the flexibility of the dimethylacrylate spacer

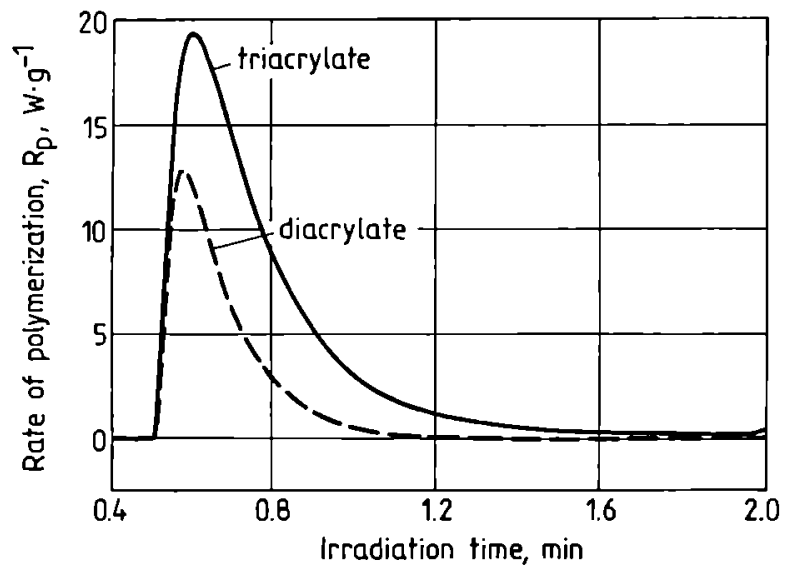

Fig. 17. Comparison of the photocuring of triacrylate and diacrylate during continuous UV exposure [127]

group allows a greater level of reaction before the network is formed. Monomers with pendant vinyl group exhibit a greater mobility, and lead to a highest extent of polymerization reaction.

The kinetic model of gelation does not assume the functional groups in multifunctional monomers to be equireactive, whereas in contrast, the homogeneous model assumes equal reactivity of all double bonds present in a monomer [3]. In Fig. 18 is shown the kinetic model

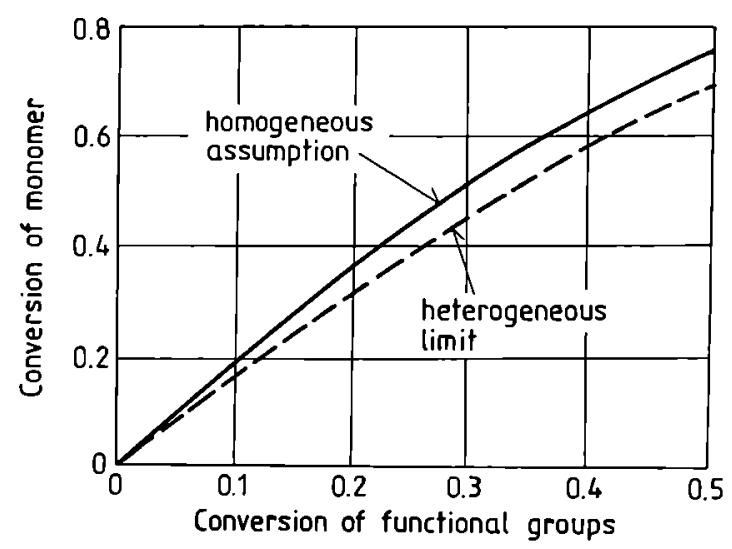

Fig. 18. Kinetic gelation model prediction

prediction for homogeneous and heterogeneous assumptions. For example, at $50 \%$ conversion of the functional groups, the homogeneous assumption predicts that $75 \%$, whereas the heterogenous predicts $69 \%$ of the monomer, has at least one double bond reacted and is unextractable [3].

End note: This article has been written by Dr. Julita Jakubiak, Head of the joint project "Mechanisms, kinetics and applications of photopolymerization initiated by visible light photoinitiators", supervised by Prof. J. F. Rabek and Prof. J. P. Fouassier. Dr. J. Jakubiak spent one year 
(1998/1999) as post-doc researcher at Polymer Research Group, Department of Dental Biomaterial Science, Karolinska Institute, The Royal Academy of Medicine, Stockholm, Sweden (directed by Prof. J. F. Rabek) and one year (1999/2000) as post-doc researcher at the Laboratoire de Photochimie Generale, CNRS, University of Mulhouse, France (directed by Prof. J. P. Fouassier).

\section{REFERENCES}

[1] Jakubiak J., Rabek J. F.: Polimery 2000, 45, 659. [2] Kloosterboer J. G.: Adv. Polym. Sci. 1988, 84, 1. [3] Anseth K. S., Newman S. M., Bowman C. N.: Adv. Polym. Sci. 1995, 122, 179. [4] Bastide J., Leibler L.: Macromolecules 1988, 21, 2647. [5] Funke W.: Br. Polym. J. 1989, 21, 107. [6] Matsumoto A., Matsuo H., Ando H., Oiwa M.: Eur. Polym. J. 1989, 25, 237. [7] Anseth K., Bowman C. N., Peppas N. A.: J. Polym. Sci. Chem. Ed. 1994, 32, 139. [8] Anseth K. S., Anderson K. J., Bowman C. N.: Makromol. Chem. Phys. 1996, 197, 833. [9] Anseth K. S., Bowman C. N.: Chem. Eng. Sci. 1994, 49, 2207. [10] Dusek K. in: "Advances in Polymerization" (ed., Haward R. N.), Applied Science Publications, London 1982.

[11] Kannurpatti A. R., Anseth J. W., Bowman C. N.: Polymer 1998, 39, 2507. [12] Simon G. P., Allen P. E. M., Bennett D. J., Wiliams D. G. R., Wiliams E. H.: Macromolecules 1989, 22, 3555. [13] Wilson T. W.: J. Appl. Polym. Sci. 1990, 40, 1195. [14] Simon G. P., Allen P. E. M., Williams D. R. G.: Polymer 1991, 32, 2577. [15] Matsuoka S.: "Relaxation Phenomena in Polymers", Hanser Publisher, New York 1992. [16] Dotson N. A., Macosco C. W., Tirrel M. in: "Synthesis, Characterization and Theory of Polymeric Network and Gels" (ed., Aharoni S. M.), Plenum Press, New York 1992, p. 319. [17] Dusek K., MacKnight W. J. in: "Crosslinked Polymers, Chemistry, Properties and Applications" (eds., Dickie R. A., Labana S. S., Bauer R. S.), ACS Symposium Series, No. 367, American Chemical Society, Washington, DC 1988, p. 2. [18] Dusek K., Ilavsky M.: J. Polym. Sci. Polym. Symp. 1975, 53, 47 and 75. [19] Shah A. C., Holdaway I., Parson I. W., Haward R. N.: Polymer 1978, 19, 1067. [20] Matsumoto A., Matsuo H., Oiwa M.: Makromol. Chem. Rapid Commun. 1987, 8, 373.

[21] Landin D. T., Macosko C. W.: Macromolecules 1988, 21, 846. [22] Winnik M. A.: Acc. Chem. Res. 1985, 18, 73. [23] Gibson J. E., Anseth J. W., Bowman C. N.: Proc. Conf. RadTech '99, Berlin, Germany 1999, p. 757. [24] Trommsdorff E., Kohle E., Lagally P.: Makromol. Chem. 1948, 1, 169. [25] O'Neil G. A., Torkelson J. M.: Trends Polym. Sci. 1997, 5, 349. [26] O'Neil G. A., Torkelson J. M.: Macromolecules 1999, 32, 411. [27] Soh S. K., Sundberg D. C.: J. Polym. Sci. Chem. Ed. 1982, 20, 1315. [28] Ballard M., Napper D. H., Gilbert R. G.: J. Polym. Sci. Chem. Ed. 1984, 22, 320. [29] Sack R., Schulz G. V., Meyerhoff G.: Macromolecules 1988, 21, 3345. [30] Varswell T. G., Hill D. J. T., Londero D. I., O'Donnell J. H., Pomery P. J., Winzor C. L.: Polymer 1992, 23, 137.
[31] Soh S. K., Sundberg D. C.: J. Polym. Sci. Chem. Ed. 1982, 20, 1299. [32] O'Neil G. A., Wisnudel M. B., Torkelson J. M.: AIChE J. 1998, 44, 1226. [33] Zhu S., Tian Y., Hamielec A. E., Eaton D. R.: Polymer 1990, 31, 154. [34] Parker H. Y., Westmoreland D. G., Chang H. R.: Macromolecules 1996, 29, 5119. [35] Russell G. T., Napper D. H., Gilbert R. G.: Macromolecules 1988, 21, 2141. [36] Anseth K. S., Wang C. M., Bowman C. N.: Polymer 1994, 35, 3243. [37] Russell G. T., Gilbert R. G., Napper D. H.: Macromolecules 1992, 25, 2459. [38] Russell G. T., Gilbert R. G., Napper D. H.: Macromolecules 1993, 26, 3538. [39] O'Shaughnessy B., Yu J.: Macromolecules 1994, 27, 5067 and 5079. [40] Stickler M.: Makromol. Chem. 1983, 184, 2563.

[41] Anseth K. S., Wang C. M., Bowman C. N.: Macromolecules 1994, 27, 650. [42] Faldi A., Tirell M., Lodge T. P.: Macromolecules 1994, 27, 4176. [43] Buback M., Huckestain B., Russell G. T.: Makromol. Chem. Phys. 1994, 195, 539. [44] Anseth K. S., Kline L. M., Walker T. A., Anderson K. J., Bowman C. N.: Macromolecules 1995, 28, 2491. [45] Mateo J. L., Serrano J., Bosch P.: Macromolecules 1997, 30, 1285. [46] Young J. S., Bowman C. N.: Macromolecules 1999, 32, 6073. [47] Mateo J. L., Calvo M., Serrano J., Bosch P.: Macromolecules 1999, 32, 5243. [48] Cardenas J. N., O'Driscoll K. F.: J. Polym. Sci., Chem. Ed. 1976, 14, 883. [49] Cardenas J. N., O'Driscoll K. F.: J. Polym. Sci., Chem. Ed. 1977, 15, 1883. [50] Soh S. K., Sundberg D. C.: J. Polym. Sci. Polym. Chem. Ed. 1982, 20, $1299,1315,1331,1345$.

[51] Cook W. D.: Polymer 1992, 33, 2152. [52] Zhu S., Tian Y., Hamielec A. E., Eaton D. R.: Macromolecules 1990, 23, 1144. [53] Okay O.: Polymer 1994, 35, 796. [54] Cook W. D.: J. Polym. Sci. Polym. Chem. Ed. 1993, 31, 1053. [55] Smoluchowski M.: Z. Phys. Chem. 1918, 92, 129. [56] Russell G. T., Napper D. H., Gilbert R. G.: Macromolecules 1988, 21, 2133. [57] Russell G. T., Gilbert R. G., Napper D. H.: Macromolecules 1993, 26, 3538. [58] Flory P. J.: "Statistical Mechanic of Chain Molecules", Interscience, New York 1969. [59] Scheren P. A. G.M., Russell G. T., Sangster D. F., Gilbert R. G., German A. L.: Macromolecules 1995, 28, 3637. [60] Benson S. W., North A. M.: J. Am. Chem. Scoc. 1959, 81, 1339.

[61] Benson S. W., North A. M.: J. Am. Chem. Soc. 1962, 84, 935. [62] North A. M., Reed G. A.: Trans. Faraday Soc. 1961, 57, 859. [63] North A. M., Reed G. A.: J. Polym. Sci. Ser. A 1969, 1, 1311. [64] Mahabadi K. H., O'Driscoll K. F.: Macromolecules 1977, 10, 55. [65] Mahabadi K. H., Rudin A.: J. Polym. Sci. Polym. Chem. Ed. 1979, 17, 1801. [66] Bowman C. N., Peppas N. A.: Macromolecules 1991, 24, 914. [67] Goodner M. D., Bowman C. $\mathrm{N}$. in: "Solvent-Free Polymerizations and Processes" (eds., Lond T. E., Hunt M. O.), ACS Symposium Series, No. 713, American Chemical Society, Washington, DC, 1998, p. 220. [68] Horie, Otagawa A., Muraoka M., Mita J.: J. Polym. Sci. Polym. Chem. Ed. 1975, 13, 445. [69] Nie J., Lindén L. A., Rabek J. F., Fauassier J. P., Morlet-Savary F., Ścigalski F., Wrzyszczyński A., Andrzejewska E.: Acta Polym. 1998, 49, 145. [70] Andrzejewska E., An- 
drzejewski M., Lindén L. A., Rabek J. F.: Polimery 1998, 43, 427.

[71] Jakubiak J., Lindén L. A., Rabek J. F.: J. Polym. Sci., Polym. Chem. Ed. 2000, 38, 876. [72] Jakubiak J., Lindén L. Å., Rabek J. F.: RadTech Europa ‘99, Berlin 1999, p. 417. [73] Andrzejewska E., Lindén L. A., Rabek J. F.: Makromol. Chem. Phys. 1998, 199, 441. [74] Nie J., Andrzejewska E., Rabek J., Ścigalski F., Wrzyszczyński A.: Makromol. Chem. Phys. 1999, 200, 1692. [75] Jakubiak J., Rabek J. F.: Polimery 2000, 45, 485. [76] Schulz G., Fischer J.: J. Makromol. Chem. 1967, 107, 253. [77] Borgwardt U., Schnabel W., Henglein A.: Makromol. Chem. 1969, 127, 176. [78] Yaraskavitch I., Brash J., Hamielec A.: Polymer 1987, 28, 935. [79] Zhu S., Hamielec A.: Macromolecules 1989, 22, 3093. [80] Li W., Hamielec A., Crowe C.: Polymer 1989, 30, 1513, 1518.

[81] Marten F., Hamielec A.: J. Appl. Polym. Sci. 1982, 27, 489. [82] Huguenin F. G. E., Klein M. T.: Ind. Eng. Chem. Prod. Res. Devel. 1985, 24, 166. [83] Batch G. L., Macosco C. W.: J. Appl. Polym. Sci. 1992, 44, 1711. [84] Kurdikar D. L., Peppas N. A.: Macromolecules 1994, 27, 4084. [85] Chiu W. Y., Carratt G. M., Soong D. S.: Macromolecules 1983, 16, 348. [86] O’Neil G. A., Wisnudel M. B., Torkelson J. M.: Macromolecules 1998, 31, 4537. [87] Batch G. L., Macosco C. W.: SPE Antec 1987, 974. [88] Tulig T. J., Tirrell M.: Macromolecules 1981, 14, 1501. [89] Rozenberg B. A.: Adv. Polym. Sci. 1985, 75, 115. [90] Yu W., van Meerwall E. D.: Macromolecules 1990, 23, 882.

[91] Sanford W. M., McCullough R. L.: J. Polym. Sci. Polym. Phys. Ed. 1990, 28, 973. [92] Mita I., Horie K.: J. Macromol. Sci. Rev. 1987, C27, 91. [93] Matsuoka S., Quan X., Bair H. E., Boyle D. J.: Macromolecules 1989, 22, 4093. [94] Chiao L., Lyon R. E.: J. Comp. Mat. 1990, 24, 739. [95] Cole K. C.: Macromolecules 1991, 24, 3093. [96] Shyichuk A. V.: J. Appl. Polym. Sci. 1996, 61, 1703. [97] Shechter L., Wynstra J., Kurkji R. P.: Ind. Eng. Chem. 1956, 48(1), 94. [98] Shyuchuk A. V., Lutsjak V. S.: Eur. Polym. J. 1995, 31, 631. [99] Dusek K., Somvarsky J. in: "Synthesis, Characterization and Theory of Polymeric Networks and Gels" (ed., Aharoni S. M.), Plenum Press, New York 1992, p. 283. [100] Miller D. R., Macosco C. W.: Macromolecules 1976, 9, 206.

[101] Macosko W., Miller D. R.: Macromolecules 1976, 9, 199. [102] Scranton A. B., Klier J., Peppas N. A.: Macromolecules 1986, 19, 1412. [103] Williams R. J. J.: Macromolecules 1988, 21, 2568. [104] Williams R. J. J., Vallo C. I.: Macromolecules 1988, 21, 2571. [105] Dotson N. A., Galvan R., Macosko C. W.: Macromolecules 1988, 21, 2560. [106] Scranton A. B., Pappas N. A.: J. Polym. Sci., Chem. Ed. 1990, 28, 99. [107] Mikos A. G., Takoudis C. G., Pep- pas N. A.: Macromolecules 1986, 19, 2174. [108] Mikos A. G., Peppas N. A.: J. Contr. Release 1986, 5, 53. [109] Shu S., Hamielec A. E.: Makromol. Chem. Macromol. Sym. 1988, 20/21, 501. [110] Mikos A. G., Takeudis C. G., Peppas N. A.: Polymer 1987, 28, 998.

[111] Tobita H., Hamielec A. E.: Macromolecules 1989, 22, 3098. [112] Zhu S., Hamielec A. E.: Macromolecules 1992, 25, 5457. [113] Zhu S., Hamielec A. E.: Macromolecules 1993, 26, 3131. [114] Zhu S., Hamielec A. E., Pelton R. H.: Makromol. Chem., Theory Simul. 1993, 2, 587. [115] Plonka A., Paszkiewicz A.: J. Chem. Phys. 1992, 96, 1128. [116] Manneville P., de Seze L.: "Numerical Methods in the Study of Critical Phenomena", Springer Verlag, Berlin 1981. [117] Hermann H. J., Landau D. P., Stauffer D.: Phys. Rev. Lett. 1982, 49, 412. [118] Bansil R., Harrmann H. J., Stauffer D.: Macromolecules 1984, 17, 998. [119] Boots H. M. J., Pandey R. B.: Polym. Bull. 1984, 11, 415. [120] Boots H. M. J., Klosterboer J. G., van de Hei G. M. M.: Brit. Polym. J. 1985, 17, 219.

[121] Boots H. M. J., Dotson N.: Polym. Comm. 1988, 29, 346. [122] Simon G. P., Allen P. E. M., Bennet D. J., Williams D. R. G., Williams E. H.: Macromolecules 1989, 22, 3555. [123] Bowman C. N., Peppas N. A.: Chem. Eng. Sci. 1992, 47, 1411. [124] Kucybala Z., Pietrzak M., Paczkowski J., Lindén L. Å., Rabek J. F.: Polymer 1996, 37, 4585. [125] Rabek J. F.: in "Radiation Curing in Polymer Science and Technology, Vol. I, Fundamentals and Methods" (eds., Fouasier J. P., Rabek J. F.), Elsevier Applied Science, London 1993, p. 453. [126] Herlihy S.: Proc. Conf. RadTech '99, Berlin, Germany 1999, p. 489. [127] Sauerbrunn S., Armbruster D. A.: Proc. Conf. RadTech '90, North America, Vol. 1, Chicago, Illinois, USA 1990, p. 303. [128] Herlihy S., Battersby G. C.: Proc. RadTech ‘94 North America, Florida, USA 1994, p. 156. [129] Sawada H.: J. Macromol. Sci. 1969, C3, 313. [130] Avrami M.: J. Chem. Phys. 1939, 7, 1103.

[131] Avrami M.: J. Chem. Phys. 1940, 8, 212. [132] Avrami M.: J. Chem. Phys. 1941, 9, 117. [133] Waters D. N., Paddy J. L.: Anal. Chem. 1988, 60, 53. [134] Tedder J. M. in: "Reactivity, Mechanism and Structure in Polymer Chemistry" (eds., Jenkins A. D., Ledwith A.), Wiley, New York 1974. [135] Moad G., Solomon D. H.: "The Chemistry of Free Radical Polymerization", Pergamon, London 1995. [136] Mateo J. L., Bosch P., Lozano A. E.: Macromolecules 1994, 27, 7794. [137] Hammett L. P.: J. Am. Chem. Soc. 1937, 59, 96. [138] Connors K. A.: "Chemical Kinetics", VCH Publisher, Weinheim 1990, p. 311.

Received 7 XII 1999. 